\title{
EUS-Guided FNA: Tips and Tricks
}

\author{
Rinkesh Kumar Bansal ${ }^{1} \quad$ Rajesh Puri² \\ ${ }^{1}$ Department of Gastroenterology \& Hepatobiliary Sciences, \\ Fortis Memorial Research Institute, Gurugram, Haryana, India \\ ${ }^{2}$ Department of Interventional Gastroenterology, Institute of \\ Digestive \& Hepatobiliary Sciences, Medanta The Medicity, \\ Gurgaon, Haryana, India
}

\begin{abstract}
Address for correspondence Rajesh Puri, MBBS, MD (med), DNB (Gastro), Department of Interventional Gastroenterology, Institute of Digestive \& Hepatobiliary Sciences, Medanta The Medicity, Sector 38, Gurgaon, Haryana 122001, India (e-mail: purirajesh1969@gmail.com).
\end{abstract}

\begin{abstract}
Keywords

- EUS

- EUS-FNA

- EUS-FNB

- needle

The development of endoscopic ultrasound (EUS)-guided fine needle aspiration (FNA) technique has been proved to be a great armamentarium to gastroenterologists and other branches including surgery, oncology, hepatology, pulmonary medicine, and internal medicine. EUS-FNA is quite safe and allows tissue acquisition from difficult anatomical locations like retroperitoneum, pancreas, and mediastinum. The current review discusses basic techniques steps of EUS-FNA including tips and tricks. Also, false negative FNA and EUS-FNA in difficult locations are discussed. We also discussed about EUS-guided fine needle biopsy.
\end{abstract}

\section{Endoscopic Ultrasound-Guided Fine Needle Aspiration}

With the advent of EUS-FNA, ${ }^{1}$ EUS has transformed into diagnostic as well as therapeutic modality. AsEUS provides access to gastrointestinal (GI) tract and organs nearby, it has evolved as a great tool to evaluate/taking tissue from these locations which are difficult for ultrasound/computed tomography-guided FNA/biopsy. Various structures approachable with EUS-FNA are mediastinum, pancreatic lesions, subepithelial gastrointestinal lesions, lymph nodes (both abdominal and mediastinal), adrenals, liver, gallbladder, and perirectal lesions. ${ }^{2-7}$ As EUS-FNA procedure is done under real time guidance, it can be performed from small (subcentimetric) lesions or in patients with difficult access (like cirrhosis with collaterals) also without significant complications. $^{8-10}$

\section{The Technique/Steps of EUS-FNA}

1. Selection of cases: Defining indications is the first and foremost thing in EUS-FNA. Generally, EUS-FNA is done for those lesions which are not easily accessible by percutaneous ultrasound and when diagnosis could not be achieved by other easier/noninvasive methods. We must also rule out contraindication. Anticoagulant and antiplatelet agents (clopidogrel) should be withheld 5 days before the procedure. EUS-FNA is high risk procedure as per British Society of Gastroenterology and European Society of Gastrointestinal Endoscopy guidelines and dose modification should be done according to thrombotic risk. In patients at low thrombotic risk, they recommend discontinuing clopidogrel 5 days before the procedure and in patients on dual antiplatelet therapy, they suggest continuing aspirin. In patients at high thrombotic risk, they recommend continuing aspirin and liaising with a cardiologist about the risk/benefit of discontinuing clopidogrel. ${ }^{11}$

Underlying coagulopathy must be corrected prior, patients with platelet counts $<50,000$ and INR $>1.5$ should receive platelet concentrates and fresh frozen plasma transfusions, respectively. All the procedures must be performed with conscious sedation (midazolam) or propofol given by the anesthesiologist. At our institute, we do all the EUS in the presence of anesthesiologist only but it can be done under moderate sedation like midazolam administered by trained nurse or endosonologist in those centers where anesthesiologist facility is not available. There is a single study for comparison of the use of general anesthesia and conscious sedation during EUS-FNA; cytological diagnosis was achieved in 73 of 88 (83\%) patients in the general anesthesia group versus 206 of 283 (73\%) in the conscious sedation group with same incidence of complication. This study cannot be recommended at present in absence of large data. ${ }^{12}$ 
Tips and tricks:

a. Define indication.

b. Correct coagulopathy.

c. Do in presence of anesthesiologist.

2. Focusing the lesion: Next step in EUS-FNA is focusing the target lesion. The lesion should be close to transducer. We should apply power Doppler to rule out any intervening vessels. It is better to use needle lock in the absence of experience or for small lesions where a rapid inward movement of needle is necessary to puncture lesion before lesion displacement as shown in - Fig. 1. It may be difficult to puncture gastric wall during transgastric FNA as it is thick and lax; again, a needle lock can be used to allow a rapid and forceful (yet controlled) jab of needle. The following data should be recorded for each patient: age, sex, site, size, and echo features, type and number of needle passes, number of slides, and complications from the procedure.

\begin{tabular}{|l|}
\hline Tips and tricks: \\
\hline a. Lesion should be close to transducer. \\
\hline b. Use power Doppler. \\
\hline $\begin{array}{l}\text { c. Use needle knock in unexperienced hands or small } \\
\text { lesions. }\end{array}$ \\
\hline d. Record detailed data. \\
\hline
\end{tabular}

3. Selection of needle: We use most of the times 22-gauge needle. Another type is 25-gauge needle, which is more maneuverable and preferable for pancreatic lesions or cirrhosis with coagulopathy. ${ }^{13}$ Another needle type is 19-gauge needle which is used for histopathological assessment. There are some issues with 19-gauge needle; it is difficult to take out from duodenum and causes more trauma. Some other modification of needle also occurred with times.

There are multiple types of fine needle biopsy (FNB) needle developed. The ProCore needles were developed later by Cook Medical to obtain tissue for histological examination and have shown good results. The ProCore needles are available in 25-, 22-, and 19-gauge sizes. These needles have a lateral opening (reverse bevel) to hook and cut tissue, thus entrapping it into the needle. ${ }^{14}$ Other needles specifically developed for histology capable of tissue acquisition include SharkCore (developed by Medtronic) which has multiple parallel cutting surfaces at the tip of needle and Acquire (Boston Scientific) which has three cutting surfaces separated by three sharp points.

Earlier studies showed that five to seven passes from pancreatic lesions and three to five passes from lymph nodes should be done for better diagnostic yield; however, later studies have shown good results with less number of passes and probably experience of endosonographer are important. ${ }^{15-18}$
Tips and tricks:

a. 22-gauge most used needle.

b. Use 25-gauge needle in the presence of collaterals/ vessels.

c. For histology, use special needle ProCore/Sharkcore/ Acquire.

4. Methods of FNA: Several modifications of basic technique have been used to increase diagnostic yield; these include suction, water suction, capillary action, door knock, and fanning method. In EUS-FNA by suction method, a suction syringe is attached to FNA needle after removal of stylet. Suction syringes are available in 5, 10, and $20 \mathrm{~mL}$ sizes. The suction is supposed to improve tissue holding against the cutting edge of EUS needle, thus drawing more

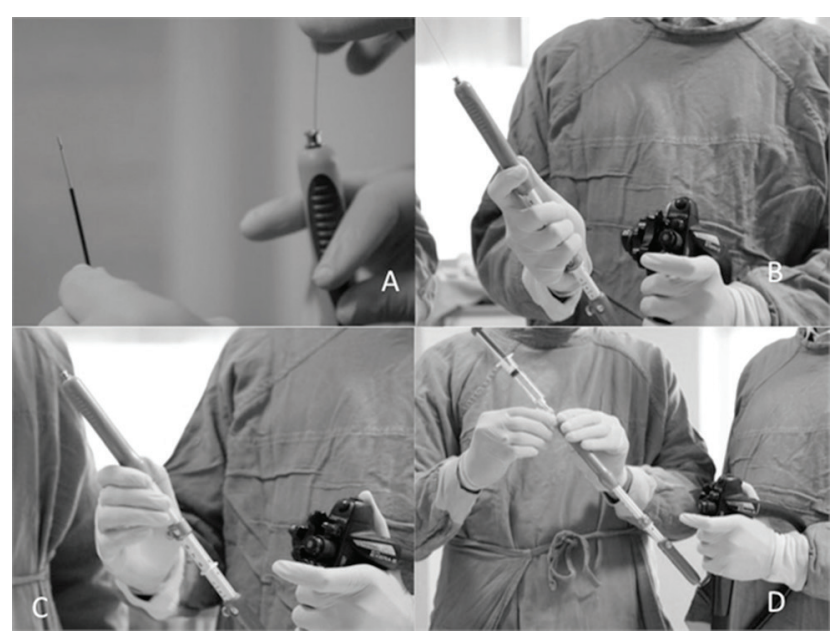

Fig. 1 (A) Needle, sheath, and stylet can be seen; (B) Lower three fingers of hand acts like a lock and thus prevent overshoot of needle; (C) Needle lock is used (in place of fingers); (D) Use of suction syringe.

cells from tissue. Suction is generally needed in fibrotic/ calcified nodes, post-treatment tubercular nodes, and in necrotic lesions. The FNA needle remains filled with air during standard suction method. The use of suction has been shown to be effective in some studies, but not in all. ${ }^{15,19-22}$

The water suction method uses a saline prefilled needle, thus contains saline inside it in place of air in routine suction method. ${ }^{23}$ The water suction method is thought to be better as it may lead to better transmission of suction in a saline column and saline solution may change surface (easier movement of aspirate) properties by coating the hollow of the needle. The gradual removal (slow pull) of stylet is thought to exert a gentle suction pressure; this technique is called capillary action. A recent randomized controlled study from our center did not show any advantage of suction over capillary action or no suction and material adequacy was equal in all three arms. ${ }^{15}$ However, the study groups consisted more of lymph nodes and less of pancreatic lesions. 
The rapid inward movement of the needle into the target lesion is called the door knock method. ${ }^{24}$ This door knock method decrease tissue displacement before the start of cutting by the needle, thus resulting in a better cut (and better cellularity). Echotexture and pathology of a target lesion may be different in different areas. Sampling from multiple areas of the target lesion is called fanning. ${ }^{25}$ The fanning is achieved by changing trajectory of the needle by the use of an elevator ( $\boldsymbol{- \text { Fig. }}$ 2). The use of stylet is thought to provide several advantages 26,27 ; it may remove material obtained from gastrointestinal wall puncture during target puncture and provide some rigidity to the needle. A blunt stylet provides additional protection to the scope channel and it helps to extract material from needle bit by bit. We follow these steps at our center; first pass is taken without suction and use of suction depends on yield of material from the first pass. Suction is avoided in patients with cirrhosis as aspirate is diluted with blood because of the inevitable presence of coagulopathy. If there are multiple sites for FNA, the most distal (which if positive proves a more advanced stage) site is selected for FNA followed by proximal sites. It is necessary to avoid false positive FNA of the distal site, so a new needle should be taken. If ${ }^{\mathrm{Q} 9}$ a lymph node is targeted, caution should be taken to avoid the primary if it is in the needle path. In the presence of multiple lymph nodes, the node with larger size/ with demarcated borders/hypoechoic in nature is preferred for FNA. A lymph node was considered reactive when FNA showed lymphoid cells in different stages of activation in the presence of adequate cellularity and the absence of granulomas/necrosis/malignant cells.

Aspiration of pancreatic cysts needs several precautions; it is done by single pass avoiding the main pancreatic duct. Antibiotic prophylaxis is used, and care is taken to avoid puncture of opposite wall (to decrease risk of bleeding) and to aspirate as much as possible. Recent randomized controlled trial suggests that there is no role of antibiotic prophylaxis before pancreatic cyst aspiration. ${ }^{28}$ In the absence of a mass

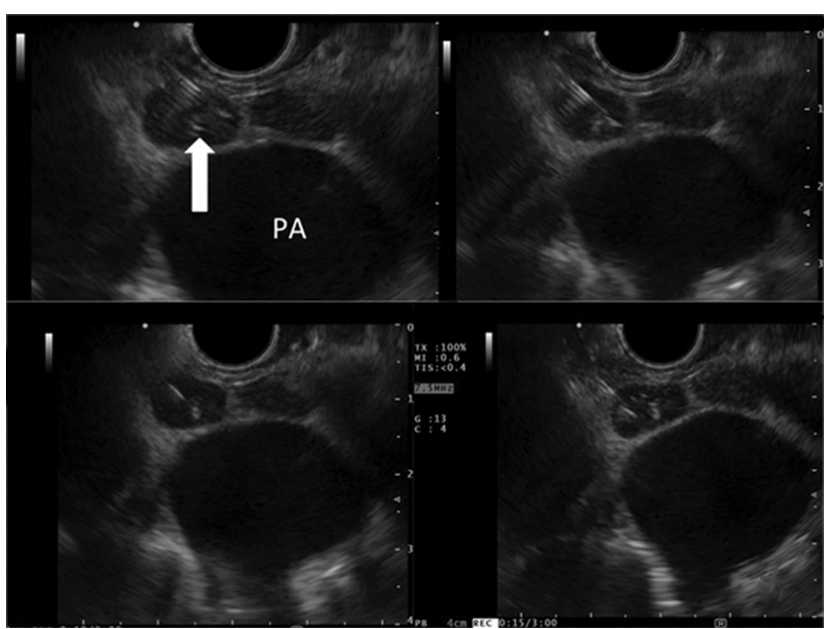

Fig. 2 Fanning in a small lymph node at aortopulmonary window, a speck of calcification is visible at the center and works as a good indicator of relative needle position; needle is seen in different trajectories from left to right of screen. like lesion (mural nodule) and in presence of multiple cysts, the largest cyst alone is aspirated. If a different cyst needs to be aspirated, a new needle should be taken. The 19-gauge needle is preferred for aspiration as it allows better aspiration due to its bigger size. The risk of bleeding after EUS-FNA is more in cysts than in solid lesions and post FNA patients should be monitored for some time. Also repositioning of the needle to aspirate all the fluid should be avoided.

The results of EUS-FNA from different locations are shown in - Table 1..$^{29-36}$ The material obtained by EUS-guided FNA remains inadequate in some cases. Many studies have been performed on techniques to improve diagnostic accuracy. Many studies have looked at type (size) of needle and diagnostic adequacy in pancreatic lesions. A meta-analysis by Madhoun et al included eight studies $(n=1292)$. The use of 25 -gauge needle was associated with statistically significant better sensitivity (0.93) as compared with 22-gauge needle (sensitivity 0.85 ). The specificity was comparable with both sizes. ${ }^{13}$ The use of fanning is shown to be associated with higher yield as compared with no fanning method. ${ }^{25}$ The water suction method was shown to be better than the standard method in one study. ${ }^{23}$ Mukai et al compared the door knocking technique (rapid movement of needle) to the standard method for pancreatic masses; the authors showed better yield in the door knocking method. ${ }^{24}$

\begin{tabular}{|l|}
\hline Tips and tricks: \\
\hline $\begin{array}{l}\text { a. Use suction specially wet suction in calcified/necrotic } \\
\text { nodes. }\end{array}$ \\
\hline $\begin{array}{l}\text { b. Use door knock in pancreatic mass/hard lesion/small } \\
\text { lesion. }\end{array}$ \\
\hline $\begin{array}{l}\text { c. Select most distal site followed by proximal sites in } \\
\text { case of multiple sites. }\end{array}$ \\
\hline
\end{tabular}

5. Post FNA: After FNA, the needle is pulled back and locked and the FNA assembly is taken out. The material inside the needle should be pushed on the slides bit by bit with the help of the stylet. One or two slides from each pass should be immediately fixed in absolute alcohol and the rest must be air dried. The slides are stained with Papanicolaou, Giemsa stain, and Ziehl-Neelsen stain (wherever required). Although immunocytochemistry markers can be applied to cell blocks, it lacks tissue architecture which is important information for some pathologies. Tissue biopsy should be undertaken in cases where there is suspicion of lymphomas, autoimmune pancreatitis (AIP), and gastrointestinal stromal tumors or in cases for EUS-guided liver biopsy as shown in - Table 2. Cell block and biopsy are sent in formalin.

Presence of a rapid on-site evaluation (ROSE) cytopathologist to evaluate material should increase diagnostic accuracy and limit the number of needle passes..$^{16,37-40}$ ROSE provides immediate evaluation of adequacy of material, thus increasing diagnostic accuracy and limiting number of needle passes. It increases diagnostic yield at centers with less experience but have not been shown to be effective at centers with larger volumes. ROSE was shown to increase diagnostic yield 
Table 1 Yield of EUS-FNA as per different target lesions in various meta-analysis or systemic reviews

\begin{tabular}{|c|c|c|}
\hline Organ [ref. no] & Studies, number of patients, results & Comments \\
\hline Pancreas [30] & $\begin{array}{l}\text { Fourty-one studies }(N=4,766) \text {, pooled sensitivity } \\
\text { of EUS for solid pancreatic mass was } 86.8 \% \text {, pooled } \\
\text { specificity of } 95.8 \% \text {. }\end{array}$ & $\begin{array}{l}\text { Table } 2 \text { deals with various techniques used } \\
\text { to increase yield. }\end{array}$ \\
\hline Pancreas, FNA vs. FNB [31] & $\begin{array}{l}\text { Eight randomized controlled studies including } \\
921 \text { patients; FNA and FNB were comparable; FNB } \\
\text { gives higher specimen adequacy than that of FNA. }\end{array}$ & $\begin{array}{l}\text { A trend toward lower technical success rate } \\
\text { and a trend toward higher diagnostic accu- } \\
\text { racy in the FNB group, compared with FNA. }\end{array}$ \\
\hline Lymph nodes [32] & $\begin{array}{l}\text { Thirty-two studies of mediastinal EUS-FNA; FNA } \\
\text { improved the sensitivity of EUS from } 84.7 \text { to } 88.0 \% \\
\text { and specificity improved from } 84.6 \text { to } 96.4 \% \text {. }\end{array}$ & $\begin{array}{l}\text { Later studies have shown better diagnostic } \\
\text { accuracy as compared with studies before } \\
2000 \text {. }\end{array}$ \\
\hline Adrenal [33] & $\begin{array}{l}\text { Seven case reports and ten case series, } n=416 \text {, } \\
\text { technical success in all. }\end{array}$ & $\begin{array}{l}\text { Adequate material in almost all of the } \\
\text { patients, include both benign and malig- } \\
\text { nant diagnosis. }\end{array}$ \\
\hline Subepithelial lesions [34] & $\begin{array}{l}\text { Seventeen studies ( } 978 \text { attempts) pooled diagnos- } \\
\text { tic rate of EUS-guided needle sampling was } 59.9 \% \text {. }\end{array}$ & $\begin{array}{l}\text { Subgroup analysis: no difference in } \\
\text { diagnostic rate among FNA, FNB, or trucut } \\
\text { needle biopsy or among different size nee- } \\
\text { dles; cell block method may have higher } \\
\text { diagnostic rate. }\end{array}$ \\
\hline Pancreatic cystic lesions [35] & $\begin{array}{l}\text { Eighteen studies, ( } n=1,438) \text { pooled sensitivity } \\
54 \% \text {, specificity } 93 \% \text { for cytology, sensitivity } 63 \% \text {, } \\
\text { and specificity } 88 \% \text { for CEA. }\end{array}$ & $\begin{array}{l}\text { Diagnostic accuracy of EUS-FNA was more } \\
\text { in prospective studies. }\end{array}$ \\
\hline $\begin{array}{l}\text { Malignant biliary stricture or cholan- } \\
\text { giocarcinoma }[36,37]\end{array}$ & $\begin{array}{l}\text { Six studies ( } n=196) \text {, pooled sensitivity of } 66 \% \text { for } \\
\text { diagnosis of cholangiocarcinoma, better sensitiv- } \\
\text { ity ( } 80 \% \text { ) if mass like lesion. }{ }^{17} \\
\text { Meta-analysis of EUS-FNA in bile duct and gallblad- } \\
\text { der cancer, nine studies ( } 284 \text { patients), a pooled } \\
\text { sensitivity of } 0.84 \text { and a pooled specificity of } 1.00 \text {, } \\
\text { area under the curve being } 0.92 \text {. }\end{array}$ & $\begin{array}{l}\text { Diagnosis of upper end biliary stricture is a } \\
\text { challenge even in cholangioscopy era. } \\
\text { EUS-FNA is very useful and also provides } \\
\text { option of lymph node FNA/staging of mass } \\
\text { lesion. }\end{array}$ \\
\hline
\end{tabular}

Abbreviations: CEA, carcinoembryonic antigen; EUS, endoscopic ultrasound; FNA, fine needle aspiration; FNB, fine needle biopsy.

Table 2 Choosing an optimal strategy for EUS-FNA/FNAB

\begin{tabular}{|c|c|c|c|}
\hline $\begin{array}{l}\text { What do we } \\
\text { need }\end{array}$ & Examples & Which needle & Comments \\
\hline $\mathrm{FNA}^{\mathrm{a}}$ & $\begin{array}{l}\text { Lymph nodes, pancreatic solid } \\
\text { masses }\end{array}$ & $\begin{array}{l}25 \text {-gauge is better for head/unci- } \\
\text { nate process of pancreas, } 22 \text {-gauge } \\
\text { standard for most of the lesions. }\end{array}$ & $\begin{array}{l}\text { Suction can be used if inadequate material } \\
\text { is in the first pass. } \\
\text { Suction is needed for necrotic lymph } \\
\text { nodes, rapid on-site evaluation (ROSE) can } \\
\text { help. } \\
\text { GeneXpert, ZN stain, and tubercular } \\
\text { culture, cell block (if lymphoma markers } \\
\text { needed) in cases of fever of unknown } \\
\text { origin. }\end{array}$ \\
\hline Tissue histology & $\begin{array}{l}\text { Subepithelial lesions, autoim- } \\
\text { mune pancreatitis, lymphoma, } \\
\text { liver biopsy. }\end{array}$ & $\begin{array}{l}\text { Use FNB needles } \\
\text { 19-gauge FNA needle can be used. }\end{array}$ & Try to look for macroscopic visible core. \\
\hline Cyst aspiration & Pancreatic cystic neoplasm. & $\begin{array}{l}19 \text {-gauge } \\
22 \text {-gauge if small cyst or difficult } \\
\text { transduodenal puncture. }\end{array}$ & $\begin{array}{l}\text { Single pass and near complete aspiration } \\
\text { without trying to sample from wall unless } \\
\text { mass lesion present, antibiotic prophylaxis. } \\
\text { Send for CEA, cytology, amylase. } \\
\text { If inadequate fluid aspirated, send for CEA. }\end{array}$ \\
\hline
\end{tabular}

Abbreviations: CEA, carcinoembryonic antigen; EUS, endoscopic ultrasound; FNA, fine needle aspiration; FNB, fine needle biopsy; FNAB, fine needle aspiration biopsy; ZN stain, Ziehl-Neelsen stain.

Repeat procedure if material is inadequate.

by 10 to $15 \%$ in earlier studies. A systemic review of 70 studies showed that use of ROSE was associated with an improvement of adequacy rates by $3.5 \% .^{39} \mathrm{~A}$ recent meta-analysis showed no extra advantage of ROSE. ${ }^{38}$ It included seven studies (1,299 patients); there was no statistical significant difference in diagnostic adequacy (sensitivity 0.91 vs. 0.85 ), yield, or number of needle passes. ${ }^{40}$

Presence of a macroscopic visible tissue core has also been shown to increase diagnostic yield. In a study by Iwashita et al, a visible core equal to or more than 4-mm macroscopic size 
was associated with superior histological, cytological, and overall higher diagnostic yield. ${ }^{41}$

EUS-FNA is a day care procedure. We generally observe for 2 hours post procedure in our recovery room situated in endoscopy suit.

\begin{tabular}{|l|}
\hline Tips and tricks: \\
\hline a. Make both alcohol-fixed and air-dried slides. \\
\hline b. Practice ROSE/ MOSE/CEUS/elastography. \\
\hline
\end{tabular}

Abbreviations: CEUS, contrast EUS; contractEUSMOSE, microscopic onsite evaluation

\section{False-Negative FNA}

False-negative sampling happens due to inadequate sampling or incorrect placement (targeting) of the needle. False negative FNA occurs commonly in patients with pancreatic masses and underlying chronic pancreatitis as chronic pancreatitis masks the distinction between the mass and the nonmalignant parenchyma. The sensitivity to identify malignancy correctly, decreases approximately $20 \%$ in the setting of chronic pancreatitis. The use of ROSE, contrast enhanced EUS, or elastography may help to increase diagnostic yield in the setting of chronic pancreatitis. ${ }^{42,43} \mathrm{Few}$ studies have evaluated the role of repeating FNA (re-FNA) after initial negative FNA. Data are mainly available for re-FNA of pancreatic lesions. Re-FNA should be attempted, especially if clinical suspicion of malignancy is high. The re-FNA of initial nondiagnostic FNA has been shown to be diagnostic in 30 to $60 \%$ of cases in various studies. ${ }^{44-46}$

\section{EUS-FNA from Difficult Locations}

-Fig. 3 shows some examples of EUS-FNA from small lesions or anatomically difficult locations. The 25-gauge needle is useful in the presence of collaterals/vessels as it should cause less trauma in case of accidental puncture. Transarterial EUS-FNA has been described ${ }^{47}$ in a few patients and can be used if no other safer method of getting tissue is available. Arteries have thick elastic and muscular walls and should not bleed in contrast to the thin wall of veins. There is less data on transvenous FNA ${ }^{48,49}$ and it should be avoided whenever possible. It may be difficult to take out thick needles (particularly 19-gauge) in the duodenum; the sheath can be taken out in the stomach and the scope is entered into the duodenum with the sheath slightly out, in such cases. Although the sheath should be kept slightly out of the scope, in some cases it may be kept more out of the scope if a vessel is present in the expected trajectory of the needle to enable the path to be seen more clearly. It may be difficult to puncture very small lymph nodes or hard lesions as they tend to slip away from the needle. The door knock technique can be applied in such cases to allow a sharp movement into the lesion. The absolute movement of needle should be noted as these lesions may move with the needle movement without the cutting action of needle. Some nodes move with respiration

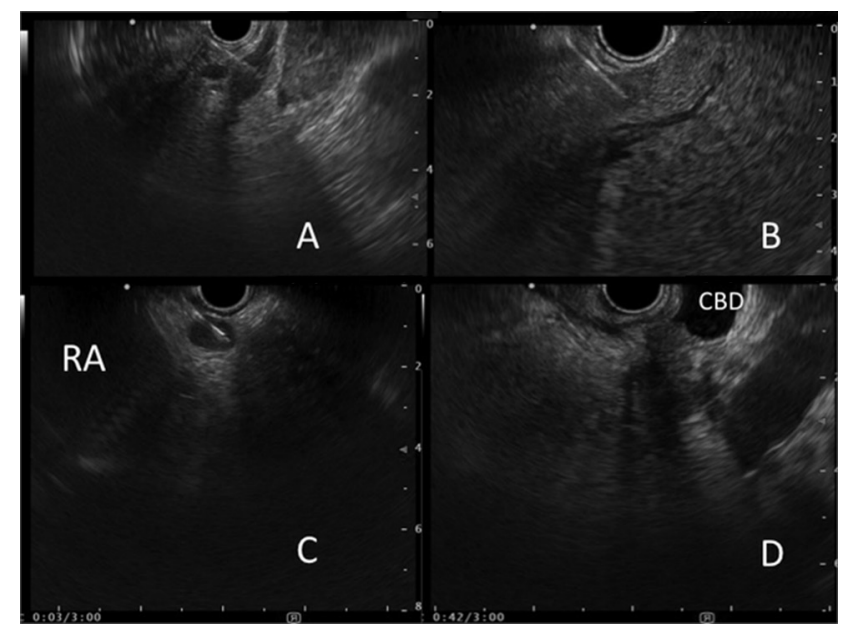

Fig. 3 FNA of small lesions/difficult locations. (A) Small focal left adrenal metastatic lesion; (B) FNA from small liver lesion; (C) FNA from a node near right atrium (RA); (D) Small pancreatic lesion infiltrating common bile duct (CBD). FNA, fine needle aspiration.

\begin{tabular}{|l|}
\hline Tips and tricks: \\
\hline $\begin{array}{l}\text { a. Use } 25 \text {-gauge needle in the presence of collaterals/ } \\
\text { vessels. }\end{array}$ \\
\hline b. Transarterial FNA feasible rather than transvenous FNA. \\
\hline $\begin{array}{l}\text { c. Consider sheath adjustment in pancreatic lesion/ } \\
\text { vessels. }\end{array}$ \\
\hline d. Use door knock in small lymph nodes or hard lesions. \\
\hline
\end{tabular}

and coordination with respiratory movements is needed for puncture.

\section{EUS-Guided Fine Needle Biopsy}

EUS-guided fine needle biopsy (EUS-FNB) is new development which samples core of the tissue. The basic difference between FNA specimen and fine needle biopsy (EUS-FNB) specimen is that in FNB tissue architecture is maintained.

The indications for FNB would be ${ }^{50}$ :

1. When FNA is inconclusive.

2. When tissue architecture is important like in cases of lymphoma and AIP.

3. When immunohistochemistry is required for the diagnosis like in cases of gastrointestinal stromal tumors and lymphoma.

4. When there is a need to perform tissue profiling or cell culture for targeted therapies.

5. In centers where ROSE facility is not available.

As we discussed previously, there are various EUSFNB needles. ${ }^{14}$ ProCore are hollow cutting needles with side-type cutting while end-type cutting needle are Franseen needle (Acquire, Boston Scientific) and fork-tip needle (SharkCore, Medtronic). Initial studies with these new needles are very encouraging, However, the current data comparing various EUS-FNB core needles for sample 
adequacy, diagnostic accuracy, and acquisition of a core specimen are scanty. ${ }^{51}$ These EUS-FNB needles are expensive and there is limited data to suggest whether these FNB needle can replace FNA or not. ${ }^{52}$

As there is an increased cellularity along with preserved histological architecture of the EUS-FNB sample, it makes an ideal sample for histological examination and molecular testing and have very promising role in liver biopsy, diseases of pancreas, liver, and GI tract.

\section{Conclusion}

EUS-guided tissue acquisition or therapies are associated with a good success rate; however, a failure requires a repeat procedure. By optimizing the technique, the need for repeat procedures can be decreased substantially.

\section{Conflict of Interest}

None declared.

\section{References}

1 Vilmann P, Jacobsen GK, Henriksen FW, Hancke S. Endoscopic ultrasonography with guided fine needle aspiration biopsy in pancreatic disease. Gastrointest Endosc 1992;38(2):172-173

2 Ge N, Zhang S, Jin Z, et al. Clinical use of endoscopic ultrasound-guided fine-needle aspiration: guidelines and recommendations from Chinese Society of Digestive Endoscopy. Endosc Ultrasound 2017;6(2):75-82

3 Tharian B, Tsiopoulos F, George N, Pietro SD, Attili F, Larghi A. Endoscopic ultrasound fine needle aspiration: technique and applications in clinical practice. World J Gastrointest Endosc 2012;4(12):532-544

4 Yoshinaga S, Suzuki H, Oda I, Saito Y. Role of endoscopic ultrasound-guided fine needle aspiration (EUS-FNA) for diagnosis of solid pancreatic masses. Dig Endosc 2011;23(suppl 1) :29-33

5 Vilmann P, Clementsen PF, Colella S, et al. Combined endobronchial and esophageal endosonography for the diagnosis and staging of lung cancer: European Society of Gastrointestinal Endoscopy (ESGE) Guideline, in cooperation with the European Respiratory Society (ERS) and the European Society of Thoracic Surgeons (ESTS) Endoscopy 2015;47(6):545-559

6 Gleeson FC, Clain JE, Rajan E, Topazian MD, Wang KK, Levy MJ. EUS-FNA assessment of extramesenteric lymph node status in primary rectal cancer. Gastrointest Endosc 2011;74(4):897-905

7 Puri R, Thandassery RB, Choudhary NS, et al. Endoscopic ultrasound-guided fine-needle aspiration of the adrenal glands: analysis of 21 patients. Clin Endosc 2015;48(2):165-170

8 Choudhary NS, Bodh V, Kumar N, et al. Yield of endoscopic ultrasound-guided fine needle aspiration for subcentimetric lymph nodes: a comparison to larger nodes. Endosc Ultrasound 2017;6(3):168-173

9 Choudhary N, Bansal RK, Puri R, et al. Impact and safety of endoscopic ultrasound guided fine needle aspiration on patients with cirrhosis and pyrexia of unknown origin in India. Endosc Int Open 2016;4(9):E953-E956

10 Choudhary NS, Puri R, Saigal S, et al. Impact of endoscopic ultrasound-guided fine-needle aspiration in prospective liver transplant recipients with hepatocellular carcinoma and lymphadenopathy. Indian J Gastroenterol 2016;35(6):465-468
11 Veitch AM, Vanbiervliet G, Gershlick AH, et al. Endoscopy in patients on antiplatelet or anticoagulant therapy, including direct oral anticoagulants: British Society of Gastroenterology (BSG) and European Society of Gastrointestinal Endoscopy (ESGE) guidelines. Gut 2016;65(3):374-389

12 Ootaki C, Stevens T, Vargo J, et al. Does general anesthesia increase the diagnostic yield of endoscopic ultrasound-guided fine needle aspiration of pancreatic masses? Anesthesiology 2012;117(5):1044-1050

13 Madhoun MF, Wani SB, Rastogi A, et al. The diagnostic accuracy of 22-gauge and 25-gauge needles in endoscopic ultrasound-guided fine needle aspiration of solid pancreatic lesions: a meta-analysis. Endoscopy 2013;45(2):86-92

14 Fuccio L, Larghi A. Endoscopic ultrasound-guided fine needle aspiration: how to obtain a core biopsy. ? Endosc Ultrasound 2014;3(2):71-81

15 Bansal RK, Choudhary NS, Puri R, et al. Comparison of endoscopic ultrasound-guided fine-needle aspiration by capillary action, suction, and no suction methods: a randomized blinded study. Endosc Int Open 2017;5(10):E980-E984

16 Erickson RA, Sayage-Rabie L, Beissner RS. Factors predicting the number of EUS-guided fine-needle passes for diagnosis of pancreatic malignancies. Gastrointest Endosc 2000;51(2):184-190

17 LeBlanc JK, Ciaccia D, Al-Assi MT, et al. Optimal number of EUS-guided fine needle passes needed to obtain a correct diagnosis. Gastrointest Endosc 2004;59(4):475-481

18 Iwashita T, Nakai Y, Samarasena JB, et al. High single-pass diagnostic yield of a new 25-gauge core biopsy needle for EUSguided FNA biopsy in solid pancreatic lesions. Gastrointest Endosc 2013;77(6):909-915

19 Lee JK, Choi JH, Lee KH, et al. A prospective, comparative trial to optimize sampling techniques in EUS-guided FNA of solid pancreatic masses. Gastrointest Endosc 2013;77(5):745-751

20 Puri R, Vilmann P, Săftoiu A, et al. Randomized controlled trial of endoscopic ultrasound-guided fine-needle sampling with or without suction for better cytological diagnosis. Scand J Gastroenterol 2009;44(4):499-504

21 Wallace MB, Kennedy T, Durkalski V, et al. Randomized controlled trial of EUS-guided fine needle aspiration techniques for the detection of malignant lymphadenopathy. Gastrointest Endosc 2001;54(4):441-447

22 Wani S, Muthusamy VR, Komanduri S. EUS-guided tissue acquisition: an evidence-based approach (with videos) Gastrointest Endosc 2014;80(6):939-959.e7

23 Attam R, Arain MA, Bloechl SJ, et al. "Wet suction technique (WEST)": a novel way to enhance the quality of EUS-FNA aspirate. Results of a prospective, single-blind, randomized, controlled trial using a 22-gauge needle for EUS-FNA of solid lesions. Gastrointest Endosc 2015;81(6):1401-1407

24 Mukai S, Itoi T, Ashida R, et al. Multicenter, prospective, crossover trial comparing the door-knocking method with the conventional method for EUS-FNA of solid pancreatic masses (with videos) Gastrointest Endosc 2016;83(6):1210-1217

25 Bang JY, Magee SH, Ramesh J, Trevino JM, Varadarajulu S. Randomized trial comparing fanning with standard technique for endoscopic ultrasound-guided fine-needle aspiration of solid pancreatic mass lesions. Endoscopy 2013;45(6):445-450

26 Gimeno-García AZ, Paquin SC, Gariépy G, Sosa AJ, Sahai AV. Comparison of endoscopic ultrasonography-guided fine-needle aspiration cytology results with and without the stylet in 3364 cases. Dig Endosc 2013;25(3):303-307

27 Wani S, Early D, Kunkel J, et al. Diagnostic yield of malignancy during EUS-guided FNA of solid lesions with and without a stylet: a prospective, single blind, randomized, controlled trial. Gastrointest Endosc 2012;76(2):328-335

28 Colán-Hernández J, Sendino O, Loras C, et al. Antibiotic prophylaxis is not required for endoscopic ultrasonography-guided 
fine-needle aspiration of pancreatic cystic lesions, based on a randomized trial. Gastroenterology 2020;158(6):1642-1649.e1

29 Puli SR, Bechtold ML, Buxbaum JL, Eloubeidi MA. How good is endoscopic ultrasound-guided fine-needle aspiration in diagnosing the correct etiology for a solid pancreatic mass? A meta-analysis and systematic review. Pancreas 2013;42(1):20-26

30 Wang J, Zhao S, Chen Y, Jia R, Zhang X. Endoscopic ultrasound guided fine needle aspiration versus endoscopic ultrasound guided fine needle biopsy in sampling pancreatic masses: a meta-analysis. Medicine (Baltimore) 2017;96(28):e7452

31 Puli SR, Batapati Krishna Reddy J, Bechtold ML, et al. Endoscopic ultrasound: it's accuracy in evaluating mediastinal lymphadenopathy? A meta-analysis and systematic review. World J Gastroenterol 2008;14(19):3028-3037

32 Patil R, Ona MA, Papafragkakis C, Duddempudi S, Anand S, Jamil LH. Endoscopic ultrasound-guided fine-needle aspiration in the diagnosis of adrenal lesions. Ann Gastroenterol 2016;29(3):307-311

33 Zhang XC, Li QL, Yu YF, et al. Diagnostic efficacy of endoscopic ultrasound-guided needle sampling for upper gastrointestinal subepithelial lesions: a meta-analysis. Surg Endosc 2016;30(6):2431-2441

34 Thornton GD, McPhail MJ, Nayagam S, Hewitt MJ, Vlavianos $\mathrm{P}$, Monahan KJ. Endoscopic ultrasound guided fine needle aspiration for the diagnosis of pancreatic cystic neoplasms: a meta-analysis. Pancreatology 2013;13(1):48-57

35 Navaneethan U, Njei B, Venkatesh PG, Lourdusamy V, Sanaka MR. Endoscopic ultrasound in the diagnosis of cholangiocarcinoma as the etiology of biliary strictures: a systematic review and meta-analysis. Gastroenterol Rep (Oxf) 2015;3(3):209-215

36 Wu LM, Jiang XX, Gu HY, et al. Endoscopic ultrasound-guided fine-needle aspiration biopsy in the evaluation of bile duct strictures and gallbladder masses: a systematic review and meta-analysis. Eur J Gastroenterol Hepatol 2011;23(2):113-120

37 Klapman JB, Logrono R, Dye CE, Waxman I. Clinical impact of on-site cytopathology interpretation on endoscopic ultrasound-guided fine needle aspiration. Am J Gastroenterol 2003;98(6):1289-1294

38 Wani S, Mullady D, Early DS, et al. The clinical impact of immediate on-site cytopathology evaluation during endoscopic ultrasound-guided fine needle aspiration of pancreatic masses: a prospective multicenter randomized controlled trial. Am J Gastroenterol 2015;110(10):1429-1439

39 Matynia AP, Schmidt RL, Barraza G, Layfield LJ, Siddiqui AA, Adler DG. Impact of rapid on-site evaluation on the adequacy of endoscopic-ultrasound guided fine-needle aspiration of solid pancreatic lesions: a systematic review and meta-analysis. J Gastroenterol Hepatol 2014;29(4):697-705

40 Kong F, Zhu J, Kong X, et al. Rapid on-site evaluation does not improve endoscopic ultrasound-guided fine needle aspiration adequacy in pancreatic masses: a meta-analysis and systematic review. PLoS One 2016;11(9):e0163056

41 Iwashita T, Yasuda I, Mukai T, et al. Macroscopic on-site quality evaluation of biopsy specimens to improve the diagnostic accuracy during EUS-guided FNA using a 19-gauge needle for solid lesions: a single-center prospective pilot study (MOSE study) Gastrointest Endosc 2015;81(1):177-185

42 Varadarajulu S, Tamhane A, Eloubeidi MA. Yield of EUS-guided FNA of pancreatic masses in the presence or the absence of chronic pancreatitis. Gastrointest Endosc 2005;62(5):728736, quiz 751, 753

43 Bang JY, Varadarajulu S. Neoplasia in chronic pancreatitis: how to maximize the yield of endoscopic ultrasound-guided fine needle aspiration. Clin Endosc 2014;47(5):420-424

44 Mitchell RA, Stanger D, Shuster C, Telford J, Lam E, Enns R. Repeat endoscopic ultrasound-guided fine-needle aspiration in patients with suspected pancreatic cancer: diagnostic yield and associated change in access to appropriate care. Can J Gastroenterol Hepatol 2016;2016:7678403

45 Téllez-Ávila FI, Martínez-Lozano JA, Rosales-Salinas A, et al. Repeat endoscopic ultrasound fine needle aspiration after a first negative procedure is useful in pancreatic lesions. Endosc Ultrasound 2016;5(4):258-262

46 Spier BJ, Johnson EA, Gopal DV, et al. Predictors of malignancy and recommended follow-up in patients with negative endoscopic ultrasound-guided fine-needle aspiration of suspected pancreatic lesions. Can J Gastroenterol 2009;23(4):279-286

47 von Bartheld MB, Rabe KF, Annema JT. Transaortic EUSguided FNA in the diagnosis of lung tumors and lymph nodes. Gastrointest Endosc 2009;69(2):345-349

48 Choudhary NS, Bansal RK, Puri R, Guleria M, Sud R. Endoscopic ultrasound-guided fine-needle aspiration of an aortocaval lymph node by the transcaval approach. J Dig Endosc 2016;7:158-159

49 Sofocleous CT, Schubert J, Brown KT, Brody LA, Covey AM, Getrajdman GI. CT-guided transvenous or transcaval needle biopsy of pancreatic and peripancreatic lesions. J Vasc Interv Radiol 2004;15(10):1099-1104

50 Rana A, Rana SS. Endoscopic ultrasound-guided tissue acquisition: techniques and challenges. J Cytol 2019;36(1):1-7

51 Bang JY, Hawes R, Varadarajulu S. A meta-analysis comparing ProCore and standard fine-needle aspiration needles for endoscopic ultrasound-guided tissue acquisition. Endoscopy 2016;48(4):339-349

52 James TW, Baron TH. A comprehensive review of endoscopic ultrasound core biopsy needles. Expert Rev Med Devices 2018;15(2):127-135 